method. A small proportion (1.5\%) of the total bacterial population grew weakly on Trypticase alone, a smaller number $(0.7 \%)$ grew strongly on Trypticase alone, and many fewer $(0.02 \%)$ grew on free amino acids. Monensin eliminated $89 \%$ of the Trypticase fermenters. The most numerous Trypticase utilisers were characterised and all but one of 18 isolates obtained from four sheep were spore-forming anaerobic rods from a number of different Clostridium spp. However, unlike previous isolates, none was obligately peptidolytic: their growth was stimulated strongly by soluble sugars. Their deaminative activity from Trypticase varied from nil to $68 \mathrm{nmol}$ (mg protein) ${ }^{-1} \mathrm{~min}^{-1}$. It was calculated that even the highest-activity isolate could carry out only $17 \%$ at most of $\mathrm{NH}_{3}$ production by the mixed ruminal microbial population, and therefore by far the majority of deamination was carried out by the more numerous, low-activity bacteria typical of the main species of rumen bacteria.

\section{Influence of peptides on the growth of mixed rumen microoganisms on different carbohydrates in vitro. J Wang $^{1}$, RJ Wallace ${ }^{2}$, CJ Newbold ${ }^{2}$ ('Institute of Animal Science, Chinese Academy of Agricultural Sciences, Bei- jing 100094, China; ${ }^{2}$ Rowett Research In- stitute, Bucksburn, Aberdeen AB21 9SB, $U K)$}

Many studies in vivo and in pure and mixed cultures in vitro have shown that pre-formed amino acids and peptides increased the rate or efficiency of rumen microbial growth. However, Cruz Soto et al. [1] observed that the response of cellulolytic bacteria to peptides depended on the energy source: peptides would stimulate growth on rapidly but not on slowly degraded carbohydrates. The aim of the present experiment was to test this hypothesis in mixed rumen microorganisms in vitro. Rumen fluid was taken from two rumen-fistulated sheep receiving a mixed grass hay/concentrate diet immediately before the morning feeding. The samples were mixed and diluted three-fold in buffer to provide the inoculum for incubations with glucose, xylose, potato starch, rice straw or wheat straw $(0.2 \mathrm{~g}$ in $30 \mathrm{ml})$ with added $0.17 \mathrm{~g} \mathrm{NH}_{4} \mathrm{Cl}$ or $0.3 \mathrm{~g}$ Trypticase. Gas and VFA production were determined by standard methods, and microbial growth was determined by adding $0.033 \mu \mathrm{Ci}{ }^{32} \mathrm{P}$-phosphate and measuring incorporation into particulate material. Results were calculated as the difference between incubations containing carbohydrate and those without carbohydrate, with or without added peptides.

Fermentation of wheat and rice straw was weak at $8 \mathrm{~h}$, although some stimulation by peptides was apparent, and peptides increased all measurements at $24 \mathrm{~h}$. The other carbohydrates were fermented more rapidly. Xylose and starch fermentation at 8 and $24 \mathrm{~h}$ were stimulated by peptides. Gas and VFA production from glucose was unaffected by peptides after $8 \mathrm{~h}$, whereas ${ }^{32} \mathrm{P}$ incorporation increased by $46 \%$, suggesting that energy spilling was decreased. Thus these results are not consistent with peptides stimulating growth only on rapidly degraded substrates, as was suggested by Cruz Soto et al. [1] and Russell et al. [2]. Alternative explanations must be found to reconcile many in vivo and other in vitro results. A better microbiological description may be required. For example, glucose would be fermented by a variety of species, many without a re- 
quirement for peptides, whereas Prevotella ruminicola, which requires peptides for optimal growth, is one of the few rumen bacteria to ferment xylose rapidly.

The first author acknowledges the support of EU postdoctoral fellowship CT940538.

1. Cruz Soto R, Muhammed SA, Newbold CJ, Stewart CS, Wallace RJ (1994) Anim Feed Sci Technol 49,151-161

2. Russell JB, O'Connor JD, Fox DG, Van Soest PJ, Sniffen CJ (1992) J Anim Sci 70, 3551-3561

Peptide hydrolysis by human colonic bacteria is also a biphasic process carried out by Bacteroides-like organisms. N McKain, RJ Wallace (Rowett Research Institute, Bucksburn, Aberdeen $A B 21$ 9SB, UK)

Peptide breakdown in the rumen occurs via a two-stage process. Firstly, oligopeptides are cleaved by dipeptidyl peptidases and then the resultant $\mathrm{di}-$ and tripeptides are metabolised by separate diand tripeptidases. The latter enzymes are present in several species of bacteria and in protozoa, while dipeptidyl peptidases occur predominantly in bacteria formerly known as Prevotella ruminicola and now reclassified as $P$. albensis, $P$. brevis, $P$. bryantii and $P$. ruminicola [1]. The present study was undertaken to determine if a similar pattern occurs in human colonic bacteria. Aminopeptidase activities of mixed faecal suspensions from four human donors and of 14 of the most numerous species of human colonic bacteria were measured using alanine oligopeptides and various dipeptidyl- and amino acylarylamidase substrates. The pattern of hy- drolysis of $\mathrm{Ala}_{4}$ and $\mathrm{Ala}_{5}$ in faecal suspensions suggested that the main mechanism of peptide hydrolysis was by cleavage of dipeptides. However, a significant quantity of single amino acid cleavage also occurred, which was much greater than that found in the rumen. Dipeptidyl $p$ nitroanilides and 4-methoxynaphthylamides were broken down more rapidly than amino acyl derivatives, consistent with a greater activity of dipeptidyl peptidases. The predominant Bacteroides spp. of the intestine, including $B$. fragilis, $B$. distasonis, $B$. thetaiotaomicron and $B$. vulgatus, also had greater dipeptidyl peptidase activity than amino acyl aminopeptidase activity, while Bifidobacterium, Clostridium and Enterococcus spp. had a more variable pattern of peptidase activities. Thus peptide hydrolysis in the human intestine, as in the rumen, appears to be a two-stage process which is initiated by dipeptidyl peptidases present in the most numerous Bacteroides spp. Presumably this mechanism confers an advantage to these bacteria, although the nature of that advantage is not yet known.

1. Avgustin G, Wallace RJ, Flint HJ (1997) Int J Syst Bacteriol 47, 284-288

Isolation and characterisation of peptidase and peptide permease mutants of Prevotella albensis. N Walker, $\mathrm{RJ}$ Wallace (Rowett Research Institute, Bucksburn, Aberdeen AB21 9SB, UK)

Bacteria in the group formerly known as Prevotella ruminicola, now reclassified as $P$. albensis, $P$. brevis, $P$. bryantii and $P$. ruminicola [1], play a significant role in peptide breakdown in the rumen. Specifically, they possess dipeptidyl peptidase activities which are typical of mixed rumen 